\title{
COMO SE GOVERNA A AMAZÔNIA? Redes sociais e governança ambiental em Unidades de Conservação*
}

\section{Tiago da Silva Jacaúna}

(D) https://orcid.org/0000-0001-7248-2940

(1) Universidade Federal do Amazonas (UFAM), Manaus - AM, Brasil. E-mail: tiagojacauna@ufam.edu.br

DOI $10.1590 / 3510302 / 2020$

\section{Introdução}

A política de conservação ambiental na Amazônia, direcionada para a criação de áreas protegidas, apresenta uma diversidade de atores que se articulam para administrar o uso dos recursos naturais. Em face disso, a pesquisa procurou contribuir para a compreensão de como é construída a política pública para a conservação ambiental, pois a maneira mais adequada consiste em revelar o desenho e as propriedades das redes que a constituem, segundo aquilo que pode ser chamado

\footnotetext{
*Agradeço ao CNPq (Processo 409902/2016-0) e à Fundaçáo de Amparo à Pesquisa do Estado do Amazonas (FAPEAM, Processo 062.01330/2018) por terem concedido apoio financeiro para a realização desta pesquisa. Agradeço igualmente aos pareceristas anônimos da RBCS pela leitura atenta e pelas sugestóes.
}

Artigo recebido em: 17/01/2019

Aprovado em: 01/10/2019 policy network (Marsh e Smith, 2000; Sandström e Carlsson, 2008). Ao mesmo tempo, procurou-se inferir qual o efeito dessa rede sobre a governança ambiental. Entende-se que a rede articula a feitura da política pública ao mesmo tempo em que realiza a governança a partir das relaçóes sociais.

Marsh $(1998,2008)$ distingue conceitualmente rede de política pública (policy network) e governança. Por rede de política pública compreende-se os vários níveis de intermediação entre interesses antagônicos no processo de elaboração da política, superando modelos corporativistas e pluralistas; ${ }^{1}$ por governança, as mudanças administrativas pelas quais o Estado gerencia os recursos públicos, superando o modelo hierárquico ou o modelo de mercado. Todavia, tanto a ideia de rede de política pública quanto a de governança indicam uma situação onde vários atores (grupos, instituiçôes ou organizaçôes) estão negociando, cooperando ou competindo em torno de uma questão específica da política pública, seja 
em sua elaboração, seja em sua coordenação. Assim, a rede de política pública é uma forma analítica de se compreender a governança e seus pormenores (Giraldo; Morales; Vahos, 2009).

Em essência, a rede de política pública configura-se como uma forma de ação coletiva, uma vez que os atores nela inseridos produzem relaçóes de confiança e de identidade, mobilizam recursos e participam de estruturas de oportunidades (Carlsson, 2000; Giraldo; Morales; Vahos, 2009). Assim sendo, as redes podem funcionar como canais de comunicação onde ideias, valores e práticas políticas são difundidas. Da mesma forma que a rede proporciona oportunidades para alguns, ela pode igualmente representar obstáculo para outros. A posição ocupada por cada ator na rede, a influência exercida sobre outros e o controle sobre os recursos materiais e simbólicos transacionados determina a coordenação da política pública e o direcionamento das mudanças institucionais.

As configurações locais da política ambiental, entendidas em suas dimensóes relacionais - isto é, o encontro entre atores que possuem interesses diferentes mas se articulam quando o que está em jogo são conveniências importantes para todas as partes - oferecem uma boa oportunidade para se pensar e repensar as hierarquias e relaçóes de poder, pois propiciam um diagnóstico preciso, na medida em que tornam evidentes as relaçóes estabelecidas no mundo real. A abordagem aqui proposta distancia-se com isso de uma compreensão da política focalizada em estruturas formais de poder, privilegiando em vez disso uma percepção mais detalhada dos microfundamentos da política no que diz respeito à sua feitura e coordenação. Desse ponto de vista é que seria possível contextualizar e identificar evidências sobre como a estrutura de atuação da política influencia diretamente a produção e a manutençáo de determinados recursos naturais no âmbito de Unidades de Conservaçáo ${ }^{2}$ (doravante UCs).

No estudo da política e da governança ambiental, a Análise de Redes Sociais (ARS) vem sendo empregada com bastante frequência e tem se mostrado um instrumento eficaz para a compreensão das estruturas sociais formadoras de instituições de governança, imprescindíveis para a coordenação das redes de política pública. Nesse sentido, pode-se destacar certos estudos que indicam como a estrutura da rede influencia o desempenho das instituições (Bodin, 2006; Sandström e Rova, 2010b; Sandström e Carlsson, 2008), bem como outros que avaliam o impacto da intervenção estatal nas estruturas de governança (Lubell, 2004).

Salpeteur et al. (2017) apresentam quatro contribuiçóes da ARS para o estudo da governança e do manejo de recursos naturais. A primeira é revelar a importância das características de atores específicos (stakeholders) para que se possa compreender suas funções na rede de governança. A segunda, identificar os padróes de conexão e os processos pelos quais os atores da rede se relacionam (colaboração, processo decisório, distribuição do poder político, entre outros). A terceira contribuição seria apresentar características estruturais da rede de governança que permitiriam inferir e/ou sugerir quais características podem influenciar a gestão dos recursos naturais, para que enfim se possa demonstrar as diversas escalas de governança dos recursos naturais, especialmente quando o propósito é vincular a governança local com as escalas mais altas de governança e planejamento. O presente artigo procurou avançar no estudo das duas primeiras contribuiçóes, ou seja, identificar o papel de cada ator e estabelecer como suas características influenciam a governança, no intuito de demonstrar os padrôes de conexóes entre os atores, principalmente no que diz respeito aos processos de colaboração e de distribuição do poder.

A Amazônia tornou-se um laboratório de experiências de governança dos recursos naturais e uma oportunidade para se investigar a dinâmica da política ambiental, bem como o papel dos diversos atores em sua elaboração e coordenação. Embora a política ambiental na região caracterize-se tanto por sua diversidade institucional (acordos de pesca e diferentes modelos de UCs) quanto por sua característica organização em rede (presença de vários atores, com intençôes diversas, interessados no processo de feitura e de governança das políticas ambientais), a utilização da ARS como teoria e método (Borgatti et al., 2009) não vem sendo utilizada pelos estudiosos do assunto no Brasil. Este artigo busca preencher essa lacuna e estimular o debate em torno das possibilidades heurísticas da ARS para o entendimento da política ambiental e da gestão de UCs no Brasil. 
Como sugere a literatura, as redes sociais podem funcionar como instrumentos para a análise de políticas públicas (Marques, 1999; Marsh e Smith 2000; Sandström e Carlsson, 2008; Schneider et al., 2003), sobretudo quando as próprias políticas estáo sendo formuladas a partir de redes de colaboraçáo e de negociaçáo entre diferentes atores. As redes sociais aqui estudadas configuram-se como um conjunto de atores (referenciado como nós) ligados uns aos outros por meio de inúmeros tipos de relaçóes sociais (amizades, parentesco, profissão, entre outros). Essas relaçôes podem ser analisadas tanto segundo os padrões estruturais que fundamentam as relações, quanto segundo a dinâmica que as caracterizam, desde que o foco esteja concentrado na relaçấo entre os atores e não nos atributos individuais. Dessa forma, o objetivo principal deste estudo é examinar como os atores estấo posicionados no interior da rede e como as relaçôes se estruturam dentro dos padrões gerais da rede (Scott, 2000; Wasserman e Faust, 1994). ${ }^{3}$

\section{ARS e Governança ambiental}

As redes sociais săo formadas por diversos atores que necessitam de vários tipos de recursos, materiais ou imateriais (Coleman, 1990; Lin, 2001), transacionados por meio de teias de relaçóes sociais (Thatcher, 1998). Isso influencia de forma direta o padrão comportamental dos indivíduos. Nesse sentido, as redes afetam e são afetadas pelo contexto institucional, que está longe de ser um fator neutro, pois compromete as regras do jogo (Sandström e Rova, 2010a, 2010b), na medida em que as redes, enquanto relaçóes sociais, são elas mesmas uma entidade institucional (Granovetter, 2007). Ainda que os atores estejam sempre mergulhados em um conjunto de normas (North, 1990; Ostrom, 2005) a estrutura social composta por essas normas náo pode ser compreendida enquanto força que constrange os indivíduos ou vice-versa. Para resolver a referida problemática, Marsh e Smith (2000) apontam para a necessidade de uma abordagem dialética e constante das relaçóes entre rede e agência, entre rede e contexto e entre rede e os resultados de uma dada política pública.
Uma série de estudos propóem a utilizaçáo da Análise das Redes Sociais em contextos de governança dos recursos naturais, seja em contextos de livre acesso (Crona e Bodin, 2006), seja em áreas protegidas (Alexander et al. 2018; Calvet-Mir et al. 2015). Isso também tem acontecido nos estudos sobre commons (Crona e Bodin, 2006; Dougill et al., 2006). Esses estudos empregaram a análise das redes sociais com a finalidade de identificar como a estrutura das relaçôes sociais influencia direta e indiretamente a utilização dos recursos naturais, especialmente a partir das relaçôes de confiança e de colaboração. Nossa hipótese principal é que as redes podem gerar laços e práticas duráveis entre os atores sociais por meio de um longo processo de relaçóes sociais, facilitando a cooperação e a troca de recursos ou criando obstáculos.

\section{A gestáo compartilhada}

A valorização da ARS, assim como a da análise institucional nos estudos que dizem respeito à governança dos recursos naturais, tornou-se peculiarmente importante no caso de arranjos sociais fundamentados na percepção da existência de comanejo ou gestáo compartilhada. O conceito de comanejo possui diversas definiçóes. Berkes et al. (1991) o define como a divisão de poder entre o Estado e as populaçóes locais na gestáo dos recursos naturais. Singleton (1998) acrescenta que, além da divisão do poder entre o Estado e as populaçóes locais, o sistema de governança fundamentado no comanejo torna possível a descentralização da tomada de decisão e idealmente combina os pontos fortes e diminui os pontos negativos tanto do Estado quanto das populaçōes locais.

Dessa forma, a percepção do comanejo deriva da constataçáo da complexidade da gestão ambiental e da crença de que o Estado não consegue criar sozinho condiçōes satisfatórias para gerir os recursos naturais (Berkes, 2002). Foi nesse sentido que diversos autores sugeriram que, em virtude da complexidade, da mudança ambiental e da dificuldade no manejo dos recursos naturais, as instituiçóes deveriam incluir diferentes atores sociais e dividir responsabilidades em um modelo de governança baseado na cooperação. Para isso, conceitos como "comanejo", "manejo 
adaptativo" e "manejo adaptativo local" (Plummer e Fitzgibbon, 2004; Carlsson e Berkes, 2005) foram elaborados para fundamentar experiências de gestão e controle do uso de recursos naturais.

O conceito e as experiências de comanejo conferem especial destaque à governança e náo ao governo ou ao Estado. O Estado é compreendido em suas inúmeras dimensões, não como um ator coerente e único, mas sim em sua dimensão multifacetada. Ou seja, quase sempre os atores governamentais que estão envolvidos na vida real do comanejo demonstram posição favorável a tarefas conflitantes e possuem interesses e finalidades divergentes (Carlsson e Sandström, 2008). Além disso, as instituições estatais são permeáveis, estabelecendo redes entre o público e o privado mediadas por diversos tipos de relaçôes formais e informais (Marques, 1999).

A partir desse cenário a percepção de governança surge como um novo estilo de governo marcado por uma maior cooperação entre os atores governamentais, não-governamentais e privados, sem que se ignore os conflitos oriundos do processo. Nessa acepção, a forma de governo caracterizada pelo modelo hierárquico, centralizador e de mercado, deixa de ser tratada como única via, assim como o Estado é compreendido como uma instituição composta por diferentes "faces", um organismo que pode atuar em diversas frentes e com objetivos distintos. A governança é entendida como o processo pelo qual a política é produzida por numa estrutura baseada em múltiplos atores (stakeholders), para além das hierarquias formais (Pierre e Peters, 2000).

Os conceitos de governança e de comanejo incorporam os pressupostos da rede social, pois se baseiam em diferentes lógicas em vez das hierarquias político-administrativas (Carlsson e Sandström, 2008). Além disso, a partir desses conceitos, a governança dos recursos naturais é percebida como uma rede de atores conectados para criar as "regras do jogo", isto é, as instituiçóes que irão regular o uso dos recursos naturais (Sandström e Rova, 2010b). Nesse sentido, é possível entender a estrutura de governança baseada no comanejo como redes de políticas públicas (policy networks), pois podem envolver "entidades públicas, privadas, indivíduo e grupos, em um ambiente marcado pelas características institucionais, pelos padrôes de relação pré-existentes, suas posições relativas e os recursos dos diversos atores" (Marques, 1998, p. 20).

Diante do contexto a que nos referimos, os estudos sobre redes de políticas públicas e governança têm apresentado intersecçóes interessantes. $\mathrm{O}$ conceito de redes de políticas públicas tenta dar conta das várias modalidades de intermediação de interesses entre os diversos atores (governamentais, não-governamentais e privados) envolvidos na elaboração das políticas públicas, enquanto a ideia de governança tenta abordar as transformações nas funções administrativas do Estado, devendo ser compreendida portanto como uma nova forma de gerir os recursos públicos em oposição aos modelos hierárquicos e de mercado (Marsh, 2008).

No entanto, as abordagens sobre governança nem sempre são consensuais. Sørensen e Torfing (2009) apresentam quatro visóes que dominaram os debates na Europa.

A primeira delas é a de Jessop (1998). Ele compreende governança como forma de se perceber a perda do caráter "autossuficiente" do Estado e as decorrentes transformações das funções do governo em face do contexto complexo da globalização/re-localização, complexidade social e descentralização da política pública. A partir disso define três modos de regulação da sociedade: o hierárquico (pela autoridade), o econômico (pelo mercado) e o heterárquico (por redes autoorganizadas e associaçóes). Esses modos de regulação podem coexistir em sociedade. No entanto, existe na contemporaneidade a predominância da forma heterárquica de regulação e seria essa a mais nova forma de condução da sociedade. Nesse sentido a governança se define como heterarquia, ou seja, como interdependência e coordenação negociadas entre diferentes atores/organizaçóes.

A segunda abordagem sobre governança é a de Kooiman (2003) e Kickert et al. (1997), autores que possuem uma abordagem mais limitada do conceito. Para eles qualquer estrutura fundamentada em hierarquias escapa à compreensão de governança, pois o conceito só valeria para estruturas horizontais e igualitárias. 
$\mathrm{Na}$ terceira, aparecem as ideias de Rhodes (2007, 1997). O autor avalia os inúmeros níveis de governo: internacional, nacional, regional e local. Nessa conjuntura o Estado atua incentivando a participaçáo de grupos dos setores privados e da sociedade civil, tomando parte apenas na prestação de serviços e em decisôes estratégicas. Logo, a governança nesse sentido seria formada por uma rede de instituiçôes e de indivíduos que colaboram entre si, em um contexto de confiança, formando redes semiautônomas e/ou autogovernadas, o que faz delas um desafio para a governabilidade e resistentes a alguma orientação central.

Finalmente, Pierre e Peters (2000) e Meuleman (2009) definem governança como múltiplas possibilidades de gestão que compreenderiam a totalidade das interaçóes entre a sociedade civil e os setores público e privado. Embora o conceito de governança tenha ganhado notoriedade principalmente a partir da década de 1990, ele não é novo. Novas são as recentes configuraçóes da governança e o papel do Estado nesse cenário (Pierre e Peters, 2000). A compreensão de governança como o compartilhamento de poder por diferentes atores e instituiçôes tem se tornado lugar comum. Sua estrutura pode porém apresentar diferentes configuraçôes, pois até mesmo sistemas hierárquicos podem ser considerados estruturas de governança.

A identificação empírica dessa estrutura torna-se portanto um desafio tão grande quanto o preciso diagnóstico de quais os papéis reais desempenhados pelos diversos atores. A única certeza é que a governança se oferece como um novo quadro conceitual para se entender o processo de tomada de decisáo e a implementação de políticas públicas. Um quadro gerado pelas transaçóes entre múltiplos atores com interesses divergentes, envolvidos em um contexto de intercâmbio de conhecimentos, recursos, ideias e normas.

\section{Métodos de pesquisa}

\section{Área de estudo}

O trabalho empírico foi realizado em três UCs da região do Baixo Rio Negro, no estado do Amazonas. São elas: Parque Nacional (PARNA) do Jaú (proteção integral), Reserva Extrativista (RESEX) do Rio Unini (uso sustentável) e Reserva de Desenvolvimento

Figura 1

\section{Área de Estudo}

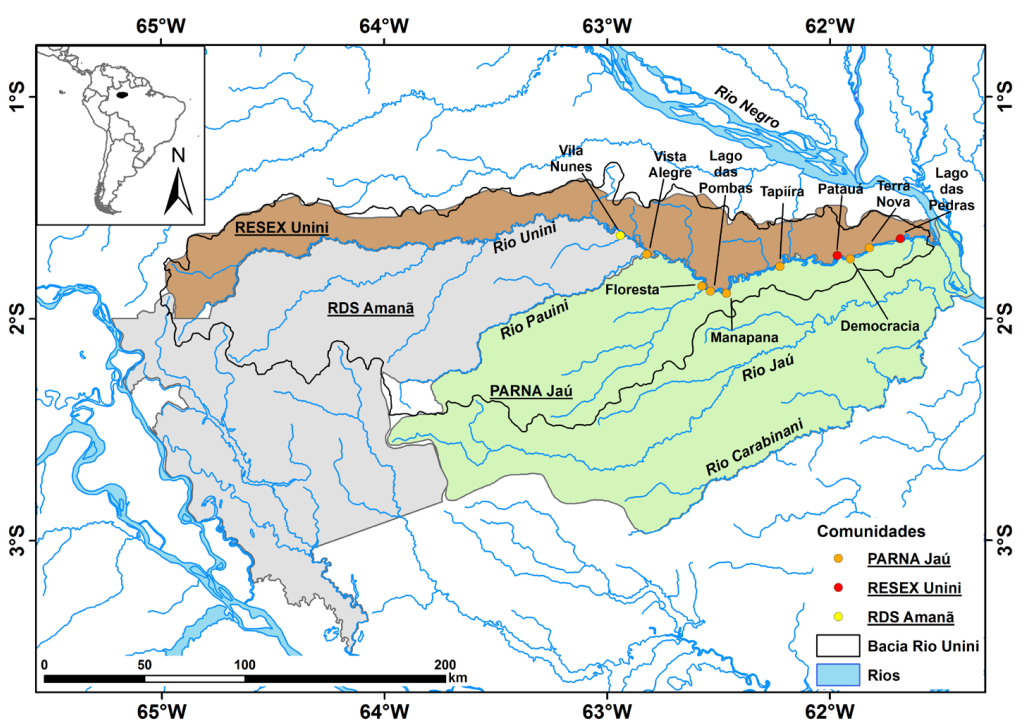

Fonte: Elaborado por Marcelo A. dos Santos Jr./FVA. 
Sustentável (RDS) do Amanã (uso sustentável) (Figura 1). A regiâo integra o Corredor Central da Amazônia 5 e o Mosaico de Áreas Protegidas do Baixo Rio Negro. ${ }^{6}$ A região do rio Unini pertence ao município de Barcelos (401,7 km de distância de Manaus), já a foz do referido rio está a $220 \mathrm{~km} \mathrm{da}$ capital do estado do Amazonas, Manaus, em linha reta.

As referidas UCs foram criadas em momentos diferentes. O Parque Nacional do Jaú foi criado em 24 de setembro de 1980 pelo Decreto Federal $\mathrm{n}^{\circ}$ 85.200. Ele abrange os municípios de Barcelos e Novo Airão. Seu limite se estende à margem direita do rio Unini. A Reserva Extrativista do Rio Unini foi criada por meio de Decreto Federal s/n no dia 21 de junho de 2006, na margem esquerda do rio Unini. Está localizada no município de Barcelos. A criação da RESEX foi pensada para dar alternativa aos moradores da margem direita do rio Unini, dentro dos limites do Parque Nacional do Jaú, caso fossem obrigados a deixar o "lado do parque", ${ }^{7}$ pois trata-se de uma área de proteçáo integral, na qual a residência humana é portanto proibida. A Reserva de Desenvolvimento Sustentável do Amanã foi criada pelo Decreto Estadual no 19.021 de 4 de agosto de 1998 e abrange os municípios de Barcelos, Coari, Codajás e Maraá.

Através dessas UCs é possível entender a atuação de múltiplos atores e redes na formulação e difusão desses distintos modelos de UCs na Amazônia. Eles operam por meio de mecanismos de difusão vertical e horizontal da política ambiental (Jacaúna, 2018). Nesse sentido, o rio Unini é um exemplo de como a articulaçáo política de diversos atores pode produzir uma diversidade institucional em um mesmo espaço. ${ }^{8}$

\section{Coleta de dados}

Os dados foram coletados entre os anos de 2013 e 2014, por meio de entrevistas e questionários sociométricos. Em consonância com a abordagem bottom-up, a amostra (não-probabilística) foi encontrada com a técnica de entrevista do snowballing (Hjern e Porter, 1997; Carlsson, 2000). Esta elege como unidade de análise apenas a rede social dos atores que realmente participam na base das atividades de gestão. A entrevista, baseada nessa técnica, inicia quando o pesquisador solicita ao entrevistado que nomeie os próximos a serem entrevistados e se encerra quando ocorrem repetiçôes de indicaçấo, obtendo-se assim o limite da rede.

Nota-se que a amostra encontrada surgiu por intermédio dos atores diretamente participantes das atividades de gestão nas UCs estudadas. A pergunta geradora de nomes, que permitiu esboçar os contornos da rede de política pública e governança analisada, foi a seguinte: "com quem o Sr./Sra. discute questōes relacionadas aos problemas, objetivos e regras da gestâo da Unidade de Conservaçấo?”. Geralmente eu completava a pergunta explicando que na resposta seria possível citar qualquer pessoa, morador ou não, da UC. Essa pergunta foi feita primeiramente a todos os atores identificados de antemáo como os mais participativos das atividades de gestão, dentre eles, os participantes dos conselhos deliberativos e consultivos, os representantes comunitários, os dirigentes e ex-dirigentes de associaçōes, bem como os atores governamentais e não-governamentais. As entrevistas se encerraram quando os nomes começaram a se repetir e novos nomes já não eram mais recorrentes.

Scott (2000) aponta para o problema de se chegar a resultados enviesados por meio da amostra baseada no snowballing, uma vez que a rede pode ser determinada pelo grupo ou ator com que se inicia a entrevista, $o$ que poderia ser diferente caso a escolha dos primeiros entrevistados fosse outra. Knoke e Kuklinski (1982) sugerem pensar na amostra separando-a por zonas, de modo que a primeira zona corresponde ao primeiro grupo de atores a serem entrevistados e a segunda seria formada pelos nomes gerados pela primeira zona, até que se forme o número de zonas que represente a diversidade dos atores envolvidos. Foi assim que mapeei previamente os grupos de atores (zonas), procurando com isso abranger toda a complexidade das atividades de governança. A partir da leitura de trabalhos anteriores (Caldenhof, 2009; Creado et al., 2008, 2012; Ferreira et al. 2007), foi possível identificar três principais grupos: os moradores, os agentes estatais e os atores de organizaçôes não-governamentais.

Para identificar a amostra, a primeira zona foi composta por representantes pré-selecionados desses três campos. A seleçấo se deu através de revisão 
bibliográfica e de observaçóes de campo. A segunda zona foi composta por nomes gerados pela primeira. A análise se concentrou nessas duas primeiras zonas porque entendeu-se que a terceira zona de atores pouco participava das atividades de gestão.

Outro dilema apresentado pela pesquisa sobre ARS - particularmente pela coleta de dados através do snowballing - é limitar (indicação fixa) ou não (livre indicação) o número de pessoas indicados pelos entrevistados para gerar a rede (Prell, 2011). Diante das duas alternativas, optou-se por deixar as pessoas livres para indicarem, pois em situaçōes onde se percebe um número pequeno de atores envolvido nas atividades de gestáo, é recomendável deixá-los livres, já que isso aumenta a possibilidade de se descobrir novos integrantes.

\section{A complexidade da governança ambiental no rio Unini}

A pesquisa encontrou quinze diferentes grupos atuando na governança do rio Unini. São eles: os moradores (24 indivíduos), o Instituto Chico Mendes de Conservação da Biodiversidade - ICMBio (com sete indivíduos), a ONG Fundação Vitória Amazônia - FVA (quatro indivíduos), o Centro de Unidades de Conservação do Estado do Amazonas - CEUC 9 (três indivíduos), a Secretaria de Estado do Meio Ambiente e Desenvolvimento Sustentável - SDS ${ }^{10}$ (dois indivíduos), e a Câmara Municipal de Barcelos, Prefeitura de Barcelos, Fundação Amazônia Sustentável - FAS, Cooperativa Xixuaú - CoopXixuaú, ONG Associação Amazônia, Conselho Nacional de Seringueiros - CNS, Associação dos Ex-moradores do Parque Nacional do Jaú - AEMPNJ, Ministério Público Federal, Wildlife Conservation Society - WCS, Central das Associaçóes de Moradores e Usuários da RDS Amanã - CAMURA (cada uma com um indivíduo).

Assim, o rio Unini reúne atores governamentais de todos os níveis (nacional, estadual e municipal), organizaçóes dos moradores da RESEX do Rio Unini, PARNA Jaú e RDS Anamã. Reúne também atores dos movimentos sociais e das organizaçóes não-governamentais. Essa configuração é característica de uma rede de política pública na qual os atores do Estado não são os únicos participantes na condução

Figura 2

Sociograma da Rede de Política Pública e Governança Ambiental do Rio Unini

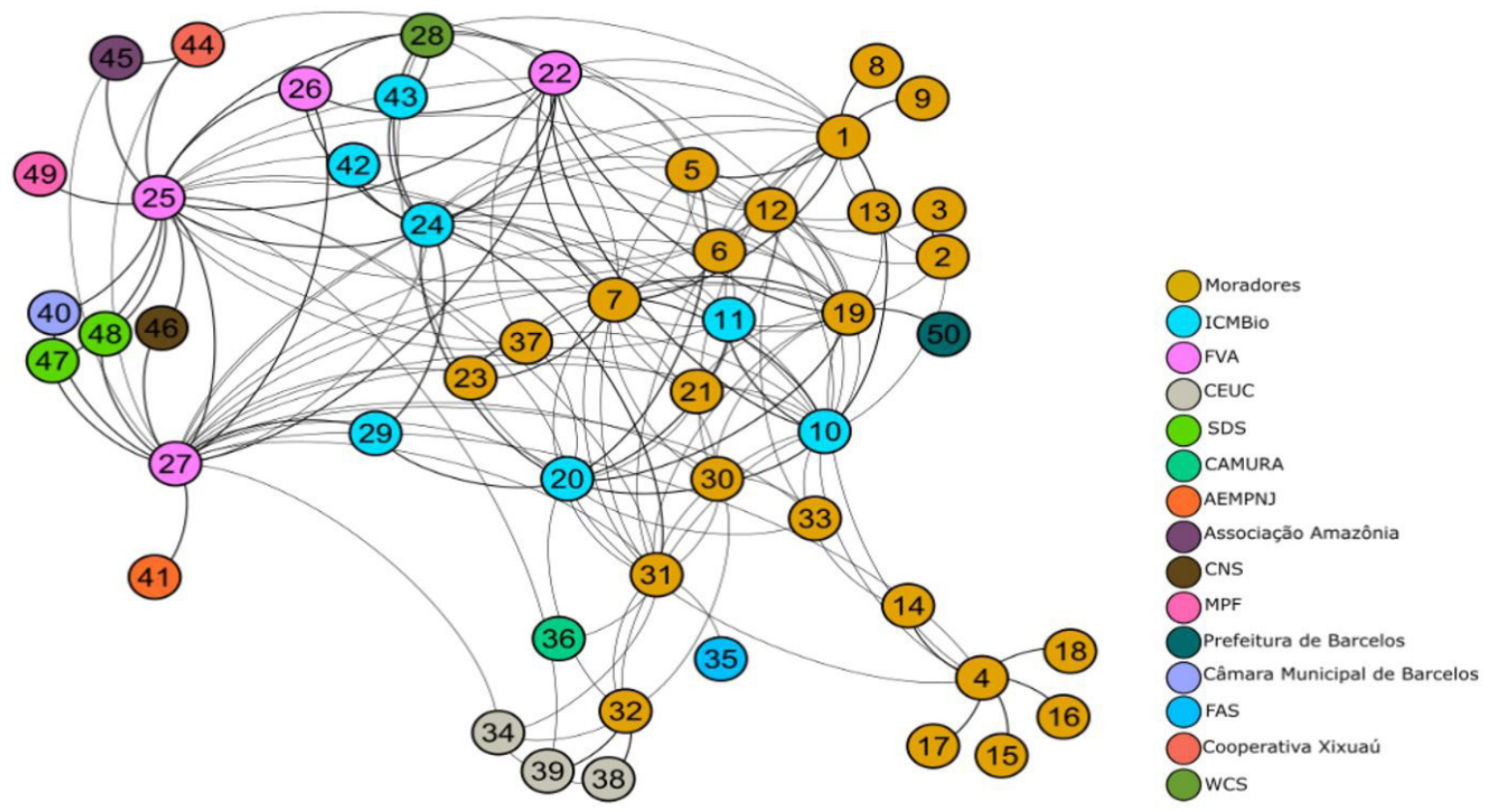

Fonte: Elaborado pelo autor com auxílio do software Gephi 0.9.2. 
da política, nem são os atores centrais na direção do processo, já que outros também ganham visibilidade e poder.

A Figura 2 exposta abaixo ilustra a rede de governança ambiental do rio Unini, representada aqui por meio de um sociograma de cinquenta vértices (nós ou atores) e 334 vínculos simétricos. A densidade da rede é de 0.14 , numa escala que vai de 0 (para uma rede sem conexão) até 1 (para uma rede totalmente conectada). Esse indicador demonstra qual a proporção do número de vínculos que estão realmente presentes na rede em relação à possibilidade total. Ou seja, para além da imagem inicial que o uso da ferramenta de ARS pode oferecer, com a representação gráfica fornecida pelo sociograma que utilizamos a seguir, torna-se possível aferir até que ponto os indivíduos da rede estão conectados uns aos outros.

\section{A influência da estrutura da rede na governança do rio Unini}

Carlsson e Sandström (2008) lançam uma importante contribuição para o entendimento de como a estrutura das redes sociais podem afetar diferentes modelos de governança. Já Sandström \& Rova (2010a, 2010b) procuram relacionar a estrutura da rede e o manejo dos recursos naturais utilizando os conceitos de redes fechadas (network closure) e redes heterogêneas (network heterogeneity). $\mathrm{O}$ primeiro conceito descreve o quão bem conectada está a rede, seja diretamente, através do número de atores conectados (densidade), seja indiretamente quando um ator específico coordena as atividades de manejo (centralidade).
Entretanto, utilizar o indicador de densidade para a compreensão do nível de fechamento requer alguns cuidados. $\mathrm{O}$ primeiro cuidado refere-se ao tamanho da rede: a literatura aponta que redes pequenas necessitam de uma alta densidade para alcançarem o mesmo nível de coesão estrutural das redes grandes (Friedkin, 1981). Assim, ao comparar densidades de redes, torna-se importante considerar o tamanho. O segundo cuidado diz respeito à existência de subgrupos, isto é, um conjunto de atores que possuem fortes e intensos laços entre eles. Uma rede pode ser considerada densa, por exemplo, em razáo de possuir vários subgrupos com alta densidade, sem que por isso deixe de ter um índice de fechamento baixo. Não obstante, uma vez que se tenha em mente as limitaçóes indicadas, a densidade da rede pode ser um bom indicador de coesão (Friedkin, 1981; Wasserman e Faust 1994; Scott 2000).

Com relação à centralização, quando maior o índice de centralização da rede, maior será o nível de fechamento. Uma medida que ajuda a complementar essa informação é o índice de centralização de intermediação, que permite entender se as relaçóes estão concentradas em um ou mais atores.

O conceito de rede heterogênea refere-se à diversidade de atores envolvidos nas atividades de manejo, no nível de trânsito e na troca de recursos entre as fronteiras/grupos (interaçóes entre grupos) das redes sociais. Desse modo, as redes heterogêneas possuem grande capacidade de mobilizar recursos, dividir trabalhos, aumentar a especialização, dividir os riscos e adquirir conhecimento ecológico (Sandström e Rova, 2010a, 2010b). Por outro lado, redes homogêneas provavelmente sofrem mais com a escassez de recursos e têm menos possibilidades de acessar novos conhecimentos ou mobilizar mais

Tabela 1

Medidas para Análise de Redes Sociais

\begin{tabular}{lcccccc}
\hline \multicolumn{1}{c}{ Redes } & $\begin{array}{c}\text { Tamanho } \\
(\mathbf{N o})\end{array}$ & $\begin{array}{c}\text { Densidade } \\
(\mathbf{\%})\end{array}$ & $\begin{array}{c}\text { Centralizaçáo } \\
\text { de Grau } \\
(\%)\end{array}$ & $\begin{array}{c}\text { Centralizaçáo de } \\
\text { intermediaçáa } \\
(\mathbf{\%})\end{array}$ & $\begin{array}{c}\text { Diversidade de } \\
\text { Atores } \\
(\mathbf{N o})\end{array}$ & $\begin{array}{c}\text { Interaçóes } \\
\text { entre grupos } \\
(\%)\end{array}$ \\
\hline $\begin{array}{l}\text { Governança do rio } \\
\text { Unini }\end{array}$ & 50 & 14 & 41 & 23 & 15 & 62 \\
\hline Formação de regras & 33 & 9,3 & 30 & 56 & 6 & 33 \\
\hline Conhecimento & 28 & 12 & 35 & 50 & 6 & 40 \\
\hline
\end{tabular}

Fonte: Elaborado pelo autor. 
recursos para enfrentar problemas. Todavia, em relação à capacidade de construir acordos e mudar e executar as regras do jogo, as redes homogêneas são mais propícias quando comparada às redes heterogêneas.

Para que se tornem compreensíveis os achados na rede de governança do rio Unini, comparo-a, conforme a Tabela 1, com as redes de formaçáo de regras e de conhecimento encontrada por Sandström e Rova, 2010a.

O tamanho da rede de governança do rio Unini é ligeiramente maior (50), porém não o suficiente para inviabilizar a comparação. Sandström e Rova (2010a) classificam as duas redes (formação de regras e conhecimento) com fechamento de moderado a baixo e alto índice de heterogeneidade. Diante desses parâmetros, analisando os índices de densidade (14\%), centralização de grau (41\%) e de intermediação (23\%), a rede de governança do rio Unini apresenta um nível de fechamento de moderado a alto, haja vista que há mais atores em posiçóes centrais da rede e menos necessidade de intermediação entre eles e o restante da rede. Ao mesmo tempo constata-se um alto índice de heterogeneidade, comprovado pelo número maior de atores (15) e de interaçâo entre grupos $(62 \%)$. Ou seja, há uma variedade maior de grupos e maior relação entre eles quando comparados às outras redes.

De acordo com o Quadro 1, devido à sua heterogeneidade, a rede de governança do rio Unini viabilizou seu acesso a uma grande diversidade de conhecimentos e recursos, como recursos financeiros públicos e privados, provindos por exemplo de projetos das ONGs e dos atores estatais, acesso ao conhecimento (advindo do trabalho contínuo de pesquisa), maior poder de mobilização junto aos órgãos públicos, maior visibilidade e maior possibilidade de enfrentar com sucesso os problemas. Além disso, pelo que indica o nível de moderado a alto do fechamento da rede, o processo de tomada de decisáo é acelerado em razáo de menores custo transacionais e da eficiência dos mecanismos de resolução de conflitos.

No entanto, a combinação entre alto nível de heterogeneidade e fechamento não implica ausência de relaçóes de poder ou de assimetrias entre os agentes da governança. Como alertam Ramia et al. (2017), existe um lado pouco tematizado das redes de governança e do papel dos atores que as configuram, pois mesmo quando as redes são legitimadas como institucionalizaçáo da cooperação, os atores podem preservar seus próprios interesses. Assim, é mister dar especial atenção à função das relaçôes de poder no interior das redes de governança.

\section{Centralidades e relaçóes de poder}

Esta é uma etapa importante no exercício de desvelar a rede de governança e a coordenaçáo da

Quadro 1

Relação entre Tipos de Estrutura de Redes com Qualidades da Governança

\begin{tabular}{|c|c|c|c|}
\hline & \multicolumn{2}{|c|}{ Rede Fechada } \\
\hline & & Baixo & Alto \\
\hline \multirow{2}{*}{$\begin{array}{c}\text { Rede } \\
\text { Heterogênea }\end{array}$} & Alto & $\begin{array}{l}\text { Nesse tipo de rede o acesso a vários tipos de } \\
\text { recursos (materiais e imateriais) é facilitado. } \\
\text { Entretanto, os custos transacionais são altos e } \\
\text { há dificuldades em estabelecer prioridades e } \\
\text { administrar conflitos entre diferentes interesses, } \\
\text { sendo estes obstáculos ao processo político. }\end{array}$ & $\begin{array}{l}\text { Alto nível de heterogeneidade promove acesso a } \\
\text { uma diversidade de conhecimentos. Ao mesmo } \\
\text { tempo, alto nível de fechamento melhora } \\
\text { o processo interno de tomada de decisão, à } \\
\text { medida que os custos transacionais são menores } \\
\text { e mecanismos de resoluçáo de conflitos são } \\
\text { facilitados }\end{array}$ \\
\hline & Baixo & $\begin{array}{l}\text { Este tipo de rede é um obstáculo para } \\
\text { o processo de governança, pois inibe a } \\
\text { possibilidade de lidar com problemas de ação } \\
\text { coletiva. Além disso, é menos provável o } \\
\text { acesso a novas ideias que ajudem a solucionar } \\
\text { problemas. }\end{array}$ & $\begin{array}{l}\text { O processo de tomada de decisão e soluçáo } \\
\text { de conflitos com baixo custo transacional é } \\
\text { possível neste tipo de estrutura. Porém, o acesso } \\
\text { e criaçáo de novas ideias é insuficiente, afetando } \\
\text { a possibilidade de encontrar soluçóes para os } \\
\text { problemas }\end{array}$ \\
\hline
\end{tabular}

Fonte: Adaptado de Sandström e Rova (2010a). 
política ambiental. Ela implica identificar quais são os atores mais importantes, quais são os responsáveis pelo funcionamento da rede e quais atores mantêm a rede conectada mesmo em momentos de crise. Ao identificarmos o papel de cada ator no interior das relaçóes de governança, teremos dados significativos para entender a divisão do poder entre os atores participantes da coordenação da política ambiental. Outra questão importante na ARS é entender os aspectos estruturais, isto é, o tipo de ligação entre os atores que compóem a rede.

Os indicadores de centralidade estão entre as medidas mais utilizadas para esse propósito (Bonacich, 1987; Borgatti, 2005; Freeman, 1979). Intuitivamente, por atores centrais, entende-se aqueles que são mais importantes e tendem a ser mais conhecidos em uma dada rede social. A depender do tipo de rede analisada, podem desempenhar papéis de líderes ou representar aqueles com acesso ao maior número de informação; por isso ganham vantagens em relação aos outros, entre outras possibilidades. Com o desenvolvimento da ARS, muitas maneiras de se medir centralidades foram criadas para auxiliar na compreensão do papel dos atores, tendo como referência a estrutura completa da rede social.

$\mathrm{Na}$ rede de política pública e governança aqui analisada, as medidas de centralidade ajudam a entender os atores e as organizaçóes que desempenham os papéis mais importantes na coordenação da política ambiental nas UCs do rio Unini. Com isso em mente nossa intenção é responder às seguintes questôes: qual a importância dos moradores, ONGs e agentes governamentais na coordenação da política ambiental? Em se tratando de uma política pública, o Estado desempenha o papel mais importante? Em se tratando de uma estrutura de governança, onde muitos atores e interesses estão em jogo, o Estado deixa de ser central e outros atores/organizaçóes assumem esse papel? A ARS possibilita um julgamento mais preciso desses pontos através das medidas de centralidade.

No estudo da distribuição do poder em uma rede de política pública e governança, o objetivo é entender se o poder está concentrado nas mãos de um único ator dominante, em um grupo de atores ou se é dividido entre atores e grupos (Adam e Hanspeter, 1999). Parte-se do pressuposto de que em um determinado momento do tempo, em um subsistema político (no caso aqui a política ambiental), um conjunto de atores têm a possibilidade de se organizarem em torno de grupos com certo grau de poder dentro do subsistema. A questão empírica é identificar quais grupos e atores detêm o "monopólio" do processo político. A análise dos indicadores de centralidade permite compreender como os atores se relacionam na rede e quais dominam o processo de elaboração e coordenação da política ambiental no rio Unini.

\section{Especificação do envolvimento dos atores: centralidade de grau}

Para essa medida não se considera a direção dos laços. Assim sendo, o que pode ser inferido da centralidade de grau é o nível de envolvimento e a atividade dos atores na rede. Na Tabela 2, apresenta-se os dez primeiros atores com maior centralidade na rede. Ou seja, os atores que são mais envolvidos nas atividades de governança do rio Unini, uma vez que foram mais contatados pelos atores que compóem a rede.

Se considerarmos os dez primeiros atores com maior centralidade de grau, encontraremos os três principais grupos de atores presentes na rede de governança do rio Unini: ONG (atores 27 e 25),

Tabela 2

Nível de Envolvimento e Atividade dos Dez Primeiros Atores na Rede de Governança

\begin{tabular}{lcc}
\hline \multicolumn{1}{c}{ Atores* $^{*}$} & $\begin{array}{c}\text { Centralidade } \\
\text { de grau }\end{array}$ & $\begin{array}{c}\text { Grau } \\
\text { Normalizado }\end{array}$ \\
\hline 27 - FVA & 26 & 53.06 \\
\hline 25 - FVA & 23 & 46.94 \\
\hline 19 - Morador & 19 & 38.78 \\
\hline 24 - ICMBio & 18 & 36.74 \\
\hline 10 - ICMBio & 18 & 36.74 \\
\hline 7 - Morador & 17 & 34.69 \\
\hline 20 - ICMBio & 16 & 32.65 \\
\hline 1 - Morador & 16 & 32.65 \\
\hline 31 - Morador & 14 & 28.57 \\
\hline $5-$ Morador & 14 & 28.57 \\
\hline $\begin{array}{l}\text { Nota: }{ }^{*} \text { O número dos atores faz referência à codificaçáo feita } \\
\text { pelo pesquisador presente na Figura 2. Fonte: Elaborado } \\
\text { pelo autor. }\end{array}$
\end{tabular}


agentes governamentais (24, 10 e 20) e moradores $(19,7,1$ e 5). Entretanto, os dois atores mais centrais na rede são representantes da ONG Fundação Vitória Amazônica. ${ }^{11}$ A grande presença de atores próximos a eles, porém, é indicativa de que os agentes governamentais (com três atores entre os dez mais ativos na rede) e alguns moradores (com quatro atores entre os mais ativos da rede) também participam de forma intensa na estrutura de governança, inclusive com um número maior de atores em relação aos da ONG. Em uma primeira análise, esses dados evidenciam uma estrutura de governança na qual os atores possuem condiçôes iguais de participação, não havendo uma estrutura hierárquica que os constranja. Além disso, demonstram uma forte cooperação. Entretanto, outros fatores podem tornar alguns atores mais importantes ou fazer com que gozem de mais prestígio do que outros, alterando assim as condiçóes e possibilidades de participação dos atores.

\section{Atores-ponte: centralidade de intermediação}

A ideia do conceito de centralidade de intermediação é especificar que em algumas situaçóes o número de pessoas que se conhecem importa menos que suas posiçôes dentro da rede. Nesse sentido, se um determinado ator está posicionado entre dois atores desconectados, ele pode tirar vantagens dessa posição e controlar o fluxo de informação para os atores desconectados. Por meio da centralidade de intermediação observa-se a frequência com que determinado ator ou organização posiciona-se entre dois outros atores. $\mathrm{O}$ indicador mede quantas vezes um determinado ator situa-se numa geodésia (menor distância) que ligue dois outros atores. Quanto mais pessoas dependerem de um determinado ator para estabelecer uma conexão, mais "poderoso" e influente será esse ator. Atores que apresentam maior centralidade de intermediaçấo podem influenciar a fluidez de informações e atuar como mediadores (Crona e Bodin, 2006) ou facilitarem interaçōes entre múltiplas escalas da governança ambiental (Rathwell e Peterson, 2012).

Mais adiante, apresento os números dos atores que possuem alguma centralidade de intermediação na rede, o que será ilustrado por meio de um

Figura 3

\section{Centralidades de Intermediaçáo da Rede de Governança do Rio Unini}

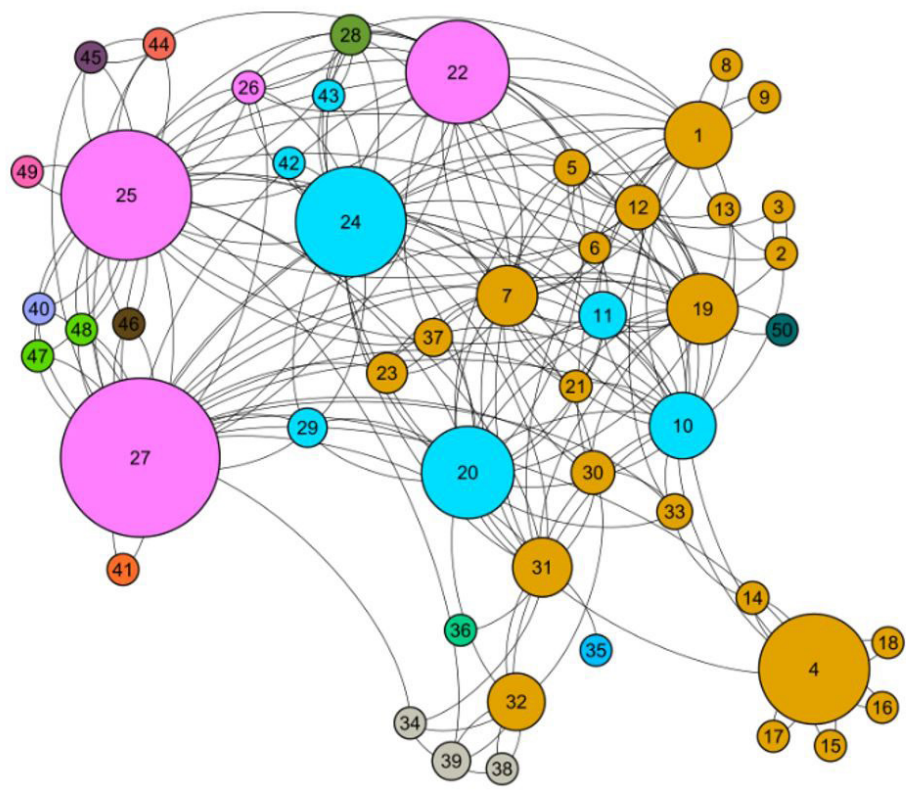

Centralidade de intermediação*
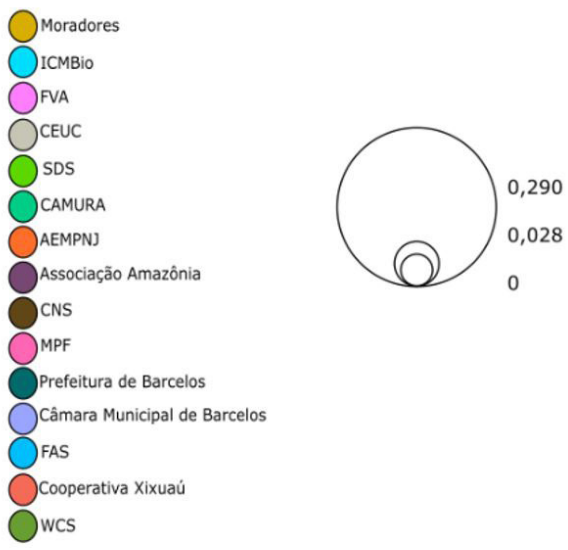

Fonte: Elaborado pelo autor com auxílio do software Gephi 0.9.2. 
sociograma, para que se possa visualizar melhor a posição desses atores. Há uma importante variação entre as centralidades de intermediação. Isso demonstra que existem atores com alto poder de influência na rede, enquanto outros ocupam um papel marginal. Novamente, os representantes da ONG Fundação Vitória Amazônica - FVA, atores 27 e 25 respectivamente, destacam-se com 0,290 e 0,200 (valores normalizados) da referida centralidade. No sociograma (Figura 3) é possível visualizar pelo tamanho dos nós a proporção dos atores relevantes na intermediaçáo das informações na rede de governança do rio Unini.

O entendimento da ideia de intermediação torna-se bastante fácil quando se visualiza a posição do ator 4 (centralidade de intermediação de 0,172 ), um morador do rio Unini. Ele serve como ponte para quatro atores à margem do restante da rede e em vista disso possui a terceira maior centralidade de intermediação. Durante a coleta de dados, percebi que esses atores fazem parte da mesma família, residindo na mesma comunidade. Sendo o ator 4 o patriarca da família, ele também lida diretamente com os assuntos políticos envolvendo a comunidade e as UCs. Apenas depois dos três primeiros atores aparece um agente governamental, representante do ICMBio, o ator 24 (centralidade de intermediação de $0,171)$. Esse cenário é interessante para que possamos compreender papel do Estado nessa situação particular de governança ambiental. Embora o Estado disponha de certo prestígio na estrutura de governança, o rio Unini tem sido controlado de maneira mais efetiva pela $\mathrm{ONG}$, o que demonstra a não-centralidade do ICMBio na condução da gestão e uma intervenção mais incisiva da Fundação Vitória Amazônica, principalmente com os atores 27 e 25.

Entre os atores do ICMBio é importante mencionar as diferentes funçôes institucionais desempenhadas por eles. São elas: o ator 10 assume a gestão da RESEX do Rio Unini; o ator 20 assume a gestão do PARNA Jaú; o ator 24, que estava afastado no momento da pesquisa, foi quem assumiu pela primeira vez a gestão da RESEX do rio Unini; o ator 11 faz parte da equipe do ICMBio no rio Unini, mas não assume função de gestão; o ator 43 participou das primeiras reuniōes para a criação da RESEX; o ator 42 assume a gestão do Parque Nacional de Anavilhanas e divide o escritório do ICMBio em Novo Airão com o pessoal atuante no rio Unini.

Analisando os indicadores já mencionados, esta é a primeira vez que o ator 24 aparece à frente dos demais membros do ICMBio (os atores 10 e 20 sempre aparecem primeiro). Isso se deve à natureza do indicador de intermediação. Ou seja, como o ator 24 assumiu pela primeira vez a gestão da RESEX do rio Unini, seu conhecimento sobre os atores e o funcionamento da governança no rio lhe confere um papel importante na intermediação das relações sociais - ou ao menos uma posiçáo de destaque frente os atores do ICMBio. Assim, ao ator do Estado cabe intermediar as relaçóes entre os moradores e o terceiro setor. Todavia, como vimos nos outros indicadores, o ator 10 , que na ocasião executava a função de gestão da RESEX do Rio Unini, já aparece como o ator de maior prestígio nos assuntos referentes à governança.

Os indicadores vêm demostrando em relação ao papel do ICMBio uma maior ocupação de espaço pelos representantes da RESEX quando comparados ao representante do PARNA. Uma das explicaçóes para isso é o entendimento de que todos os moradores do rio Unini podem usufruir dos benefícios trazidos pela RESEX, pois uma vez que se trata de um modelo mais aberto ao uso e à extração de recursos naturais, as demandas sociais recaem mais sobre a administração da RESEX que sobre a administração do PARNA.

\section{Distribuição do poder no rio Unini}

As medidas de centralidade apresentadas até aqui mostram de maneiras diversas como identificar os atores mais importantes da rede, seja no que se refere aos atores e seus imediatos contatos, seja no que se refere à relação entre o ator e a rede completa. Nesse sentido a centralidade de grau concentra-se nos contatos imediatos do ator, enquanto a centralidade de intermediação identifica a posição do ator entre dois ou mais atores. Para que uma dimensão seja bem distinguida da outras, Bonacich (1987) desenvolveu o "beta-centralidade", cálculo que permite descobrir outras possibilidades para o entendimento da centralidade e das relaçóes de poder em uma determinada rede. Nem sempre a centralidade de grau ou intermediação revela o ator mais importante ou mais poderoso da 
rede. Em alguns casos, o ator com este perfil ocupa uma posição semiperiférica, como aponta o trabalho de Cook et al. (1983).

Além disso, a descoberta dos atores importantes na rede depende da natureza das relaçôes sociais presentes no contexto relacional. É possível diferenciar entre redes sociais compostas por relaçóes positivas e negativas. Relações positivas são as redes comunicacionais medidas segundo seu fluxo de informaçáo, ou redes de influência; nesse caso um ator ganha poder e influência à medida que possui contatos com atores com maior status, sem que isso represente perda para ambos. Já relaçóes negativas são interaçôes informacionais que tendem à soma-zero, ou seja, um ator ganha enquanto outro perde; ao mesmo tempo, nesse tipo de rede social, os atores ganham poder à medida que estáo conectados com atores de menor status (ao contrário das relaçóes positivas). Redes baseadas em trocas ou barganhas e em situações nas quais as pessoas não conhecem umas às outras são as mais características desse tipo de relaçấo. Consideraçóes como essas acerca do tipo de relação social são componentes importantes da teoria das trocas em redes sociais, largamente discutidas por Bonacich (1987); Cook et al. (1983), Ikkink e Van Tilburg (1999).

A rede de governança do rio Unini é claramente uma rede de influências e de comunicação. Desde o processo de criação da RESEX do rio Unini, por exemplo, as redes foram estabelecidas através da troca de informaçóes entre os vários atores presentes (Jacaúna, 2018). Troca que aumentou com a criação dos vários fóruns deliberativos e consultivos das UCs. Nesse sentido, a criação da RESEX favoreceu o tipo de relação positiva e os atores conectados àqueles com maior status, ganhando mais poder e destaque, puderam também assumir um papel de controle e de influência na gestão. Claro que existem barganhas nas quais algum ator pode se sentir prejudicado, porém a rede de governança apresenta uma característica predominantemente colaborativa.

$\mathrm{Na}$ Tabela 3, mostro a relaçáo entre poder e centralidade, considerando uma relaçáo positiva na qual $\beta=0,079$.

$O$ número do parâmetro $\beta$ leva em consideraçáo duas variáveis. A primeira é se a relação é positiva ou negativa. A rede de governança do rio Unini apresenta predominantemente um tipo de relaçáo onde comunicação e influência são as dimensōes mais significativas, caracterizando um tipo de relaçâo positiva, na qual náo há perdas para os atores envolvidos. A segunda é indicar qual dimensão da rede seria mais importante, os atores e seus contatos próximos ou a rede completa. Um valor pequeno para o $\beta$ na equação indica uma análise sobre a estrutura local em torno do ator, enquanto valores grandes indicam mais importância do ator frente à rede completa.

A escala para o $\beta$ vai de 0 a 10 , positivo ou negativo. A Tabela 3 foi calculada com o valor $\beta=0.079$, obtido com o auxílio do software para ARS UCINET (Borgatti et al., 2002). Com um valor positivo muito próximo de zero, as relaçóes de poder e centralidade tendem à primazia da estrutura local dos atores, sinal de que nesse contexto é importante estar próximo de atores com alto índice de centralidade. Nota-se que o beta-centralidade possui uma relação conexa com o eigenvector (centralidade de autovetor), ${ }^{12}$ sendo na realidade uma extensão deste (Prell, 2011). A diferença entre os dois indicadores é o valor para $\beta$.

Uma vez que no caso aqui apresentado o valor de $\beta$ é muito próximo de zero, a ordem hierárquica dos atores apresentados na tabela acima segue com os atores 27 e 25, representantes da ONG Fundaçáo Vitória Amazônica, identificados como os atores mais influentes da rede, assumindo uma posiçấo de destaque nas relaçóes de poder. Logo em seguida estão os atores 19 e 7 , moradores locais com uma longa

Tabela 3

Poder dos dez primeiros atores

\begin{tabular}{lcc}
\hline \multicolumn{1}{c}{ Atores } & Poder & Normaliz \\
\hline $27-$ FVA & 3944 & 2,137 \\
\hline $25-$ FVA & 3863 & 2,093 \\
\hline $19-$ Morador & 3718 & 2.015 \\
\hline $7-$ Morador & 3680 & 1,994 \\
\hline $10-$ ICMBio & 3658 & 1,982 \\
\hline $24-$ ICMBio & 3629 & 1,967 \\
\hline $5-$ Morador & 3287 & 1,781 \\
\hline $20-$ ICMBio & 3255 & 1,764 \\
\hline $1-$ Morador & 3060 & 1,659 \\
\hline $22-$ FVA & 2953 & 1,600 \\
\hline
\end{tabular}

Fonte: Elaborado pelo autor. 
Quadro 2

Distribuiçáo de Poder e Tipos de Interaçáo

\begin{tabular}{|c|c|c|c|}
\hline \multirow{2}{*}{ Distribuição do Poder } & \multicolumn{3}{|c|}{ Tipos de Interação } \\
\cline { 2 - 4 } & Conflito & Barganha & Cooperaçáa \\
\hline Concentração & Dominação & Barganha Assimétrica & Cooperaçáo Hierárquica \\
\hline Fragmentação & Competição & Barganha Simétrica & Cooperaçáo Horizontal \\
\hline
\end{tabular}

Fonte: Adaptado de Adam e Hanspeter (1999).

história em atividades de representação dos interesses das comunidades do rio Unini. Também pertencentes às primeiras posiçốes são os atores $10 \mathrm{e} 24$, gestores do ICMBio, respectivamente a atual e antiga gestora da RESEX do Rio Unini, o que reafirma que as principais atividades no rio Unini passam a ser realizadas através das possibilidades engendradas pela RESEX. Nesse sentido é a tríade FVA-Moradores-ICMBio que ocupa o centro da rede de governança.

A dimensão básica da distribuição do poder encontra-se dividida entre FVA, moradores e ICMBio, com certa fragmentação que não chega a prejudicar a influência predominante da FVA. Isso é o que os dados indicam. Decidir, como propóe Adam e Hanspeter (1999), entre uma distribuição de poder concentrada ou fragmentada torna-se um desafio, como confirmam as observaçóes dos dados de governança do rio Unini. Embora a FVA domine a maioria dos indicadores de centralidade, não podemos desconsiderar o poder de mobilizaçáo dos moradores e o empoderamento conseguido ao longo dos anos. Tampouco menosprezar os atores estatais, pois suas decisóes têm peso de lei e eles dispóem do uso legítimo da força (Coleman e Perl, 1999).

Mediante uma tal análise salta à vista o poder desempenhado pela FVA na estrutura de governança do rio Unini: a formaçấo, o empoderamento e a articulação com os moradores locais, a cooperação com as agências do governo Federal na região (ICMBio). Mais recentemente o trabalho de geração de renda e alternativas econômicas, incentivado pela ONG, faz com que ela seja o principal agente na coordenaçáo da rede de política pública no rio Unini (Jacaúna, 2018), apesar de ocorrem negociaçóes constantes com os outros dois principais grupos da rede: moradores e ICMBio.

Outro aspecto importante na análise de redes de governança e política pública é identificar o tipo de cooperação entre os atores. Adam e Hanspeter
(1999) apresentam três formas de cooperação importantes: (predominância de) conflito/ competição, (predominância de) barganha/negociação e (predominância de) cooperação. Vejamos no Quadro 2 a combinação e a distribuiçáo básica do poder com cada tipo de interação.

O caso da rede de governança do rio Unini representa uma distribuição de poder fragmentada, pois nele, Estado, moradores e ONG compartilham responsabilidades no interior da referida rede. Responsabilidades que em alguns casos pode entretanto se mover para um cenário com concentraçáo do poder de influência sob o controle da FVA. Com relação ao tipo de interação, em razão do tipo de relação positiva, trata-se de uma rede de comunicação e influência, predominantemente cooperativa. Assim é mais prudente afirmar que na rede de política pública e governança do rio Unini ora vigora uma concentração de poder e uma cooperação hierárquica, ora um poder fragmentado com cooperação horizontal. Esse é diagnóstico mais adequado quando se pensa na governança local do rio Unini: a presença de conflitos, que é frequente, surge na verdade em outros níveis de governança, o estadual e o nacional, especialmente quando os atores se mobilizam na tentativa de conseguir benefícios em comum (Jacaúna, 2018).

\section{Conclusão}

Este trabalho se concentrou na apresentaçáo e na análise da estrutura da rede social da governança ambiental no rio Unini, estado do Amazonas, caracterizada por três tipos diferentes de UCs: Parque Nacional do Jaú, Reserva Extrativista do Rio Unini e Reserva de Desenvolvimento Sustentável do Amanã. Seu objetivo foi entender o papel dos diferentes atores na governança ambiental do rio Unini, bem como a 
maneira como a estrutura da rede pode influenciar a coordenação da política ambiental em UCs.

Os indicadores de densidade, centralização de grau e intermediação, diversidade e interação entre grupos permitiram compreender que a rede apresenta nível de fechamento de moderado a alto, com grande diversidade de atores. Nesse sentido, a rede tem uma tendência positiva que lhe permite acessar e mobilizar recursos provindos de diferentes atores, oriundos de instituiçôes governamentais e não-governamentais inseridos no processo de governança ambiental. A julgar pelo fechamento da rede, a proximidade entre eles diminui os custos organizacionais, melhora o processo interno de tomada de decisão e facilita os mecanismos de resolução de conflitos.

A distribuição do poder oscila entre a fragmentação e a concentração, sendo uma ONG a principal articuladora dos empreendimentos de governança no local. O tipo de interação entre os atores é eminentemente cooperativo, ora com predomínio da referida ONG, ora com funcionamento mais horizontal. A maneira como as redes sociais estão configuradas de fato influencia a forma como a governança é processada. Dependendo das disposiçóes, da densidade das relaçóes, da diversidade e do tipo de interação entre os atores, os problemas e a mobilização dos recursos podem ser facilitados ou dificultados.

Entender a estrutura das redes sociais, além de permitir encontrar possíveis fragilidades no processo de coordenação das políticas públicas, auxilia na compreensão dos diversos modelos de governança. Devido ao papel central que as UCs desempenham na política ambiental e nos desafios mundiais do desenvolvimento sustentável, os resultados apresentados não estão limitados ao rio Unini e às UCs que o compóem, mas sim podem servir de parâmetro para o estudo de outros contextos de governança ambiental. Nesse sentido, a ARS se propóe como um campo frutífero e de potencial revelador para o estudo da governança e das políticas públicas.

\section{Notas}

1 Os modelos corporativistas e pluralistas buscam compreender a relação entre Estado, classes sociais e mercado. Em linhas gerais, esses modelos podem ser distinguidos pelo peso dado ao Estado no processo de organização social. Enquanto para os teóricos corporativistas o Estado é o núcleo da análise, para os pluralistas a análise incide sobre os grupos sociais que pressionam o Estado. Porém, as possíveis oposiçóes analíticas entre os modelos não são consensuais. Reis (1995), por exemplo, ressalta que ambos têm a preocupação de evitar tanto o estatismo quanto o individualismo, característica que os fazem semelhantes. Assim, torna-se difícil estabelecer uma definitiva separação entre os dois modelos.

2 A Lei Federal No 9.985, de 18 de julho de 2000, que regulamentou o Sistema Nacional de Unidades de Conservação (SNUC) divide os modelos de Unidades de Conservação (UCs) em Proteção Integral e Uso Sustentável. Em linhas gerais, as principais características das UCs de Proteção Integral é não permitir a presença humana, já que sua área é destinada à conservaçáo da biodiversidade e à pesquisa científica. Em alguns casos são permitidos o turismo e a educaçáo ambiental, como em Parques Nacionais, Estaduais e Municipais. Além dos Parques, fazem parte dessa categoria: Estação Ecológica (EE), Reserva Biológica (REBIO), Monumento Natural e Refúgio da Vida Silvestre (RVS). As UCs de Uso Sustentável são mais flexíveis e foram pensadas tanto para garantir a conservação da biodiversidade, quanto para o extrativismo de recursos naturais. Assim, permitem a presença humana, o turismo, a educação ambiental e a extração de produtos madeireiros e náo-madeireiros, de acordo com o plano de gestão das UC. Fazem parte dessa categoria: Área de Proteção Ambiental (APA), Área de Relevante Interesse Ecológico (ARIE), Floresta Nacional/Estadual (Flona/Flota), Reserva Extrativista (RESEX), Reserva de Fauna (RF), Reserva de Desenvolvimento Sustentável (RDS) e Reserva Particular do Patrimônio Natural (RPPN).

3 A história da ARS é longa e perpassa muitas áreas do conhecimento, tais como a Matemática, a Psicologia, a Antropologia e a Sociologia. Mais recentemente tem sido derivada para aplicaçôes na Física, na Biologia, nas ciências da informação, entre outras. Freeman (2004), por exemplo, afirma que sua história remonta a 1736, com o início da teoria dos grafos de Leonard Paul Euler, passando por Georg Simmel e chegando até o surgimento mais recente de uma possível ciência das redes. Para maiores detalhes, ver: Freeman (2004), Scott (2000), Wasserman e Faust (1994) e Prell (2011).

4 Das 22 comunidades que compóem a Reserva de Desenvolvimento Sustentável do Amanã, apenas a comunidade de Vila Nunes está localizada no rio Unini.

5 Corredores Ecológicos são áreas que possuem ecossistemas prioritários e viáveis para a conservação da biodiversidade da Amazônia e da Mata atlântica. O Corredor Central da Amazônia está localizado integralmente no estado do Amazonas, lugar onde se priorizou a implementação de UCs. Está dividido em cinco sub-regióes, que apresentam características similares, considerando a 
organização social de que já dispóem: Alto Solimões, Médio Solimões, Baixo Solimóes, Uatumã e Rio Negro.

6 O Mosaico de Áreas Protegidas do Baixo Rio Negro (MBRN) foi reconhecido segundo a Portaria n.483 de 14 de dezembro de 2010. Sua área agrega 11 UCs municipais, estaduais e federais de categorias diferentes e possui 7.412.849 hectares.

7 Para detalhes dos mecanismos políticos de criação dessas UCs ver Jacaúna (2018).

8 Os modelos RESEX e RDS são categorizados como uso sustentável e possuem conceitos e objetivos idênticos, além de ambos surgirem por demanda da sociedade civil, seja do movimento de seringueiros, seja de cientistas adeptos da biologia da conservação (Jacaúna, 2018). A principal diferença entre os modelos está no regime de propriedade. No modelo RESEX, terras particulares são proibidas. O Estado precisa indenizar os proprietários e conceder todas as terras para uso coletivo. Já no modelo RDS, o Estado fica desobrigado de indenizar áreas particulares localizadas no interior da UC.

9 Em 2015 o CEUC foi extinto durante a Reforma Administrativa do então governador José Melo, transformando-se em Departamento de Mudanças Climáticas e Gestão de UC (DEMUC), subordinado à Secretaria do Estado do Meio Ambiente (SEMA).

10 Em 2015, em razão da Reforma Administrativa do então governador José Melo, a SDS passa a ser chamada de Secretaria Estadual de Meio Ambiente (SEMA).

11 A Fundação Vitória Amazônica atua na regiāo desde 1998 e desde então desempenha papel decisivo na condução e na difusão de instrumentos de política ambiental na área do rio Unini, contando uma forte articulação com os moradores e atores estatais. Para mais detalhes, ver Jacaúna (2018).

12 Diferente do indicador que mede a centralidade de grau dos atores, o eigenvector não mede a centralidade dos atores em si, mas a dos outros atores que estão imediatamente adjacentes. Isso significa que terá o maior eigenvector aquele que estiver conectado aos atores com maior centralidade de grau. Como afirma Prell (2011), o eigenvector expande a noção de centralidade de grau, pois seu resultado advém da soma dos atores conectados a outros, tendo como base a referida centralidade e não apenas a soma dos atores diretamente conectados a um único ator.

\section{REFERÊNCIAS}

ADAM, Silke \& HANSPETER, Kriesi. (1999), "The Network Approach”, in P. A. SABATIR (org.)
Theories of the policy process. Boulder, Westview Press, p. 129-154.

ALEXANDER, Steven, EPSTEIN, Graham; BODIN, Örjan; ARMITAGE, Derek \& CAMPBELL, Donovan. (2018), "Participation in planning and social networks increase social monitoring in community-based conservation", in Conservation Letters 11(5): e12562.

BERKES, Fikret. (2002), "Cross-Scale Institutional Linkages: perspectives from the bottom up", in E. Ostrom et al. (orgs.), The Drama of the Commons, National Academy of Sciences, p. 293-321.

BERKES, Fikret; GEORGE, Peter; PRESTON, Richard. (1991), Co-management: the evolution of the theory and practice of joint administration of living resources. Program for Technology Assessment in Subarctic. Ontario, McMaster University, 1991.

BODIN, Örjan. (2006), A network perspective on ecosystems, societies and natural resource management. Tese de Doutorado. Stockholm University, Suécia.

BONACICH, Phillip. (1987), "Power and centrality: a family of measures", in American Journal of Sociology I, 92(5): 1170-82.

BORGATTI, Stephen; MEHRA, Ajay; BRASS, Daniel \& LABIANCA, Giuseppe. (2009), "Network analysis in the social sciences", in Science, 323(5916): 892-895.

BORGATTI, Stephen. (2005), "Centrality and network flow", in Social Networks, 27(1): 55-71.

BORGATTI; Stephen; EVERETT, Martin \& FREEMAN, Linton. (2002), Ucinet for Windows: software for social network analysis. Harvard, MA, Analytic Technologies.

CALDENHOF, Satya. (2009), "Reserva Extrativista do Rio Unini : conflitos e estratégias socioambientais no rio Negro/AM”. Dissertação de mestrado. Universidade Federal do Amazonas, Manaus.

CALVET-MIR, Laura; MAESTRE-ANDRÉS, Sara; MOLINA, José Luis \& VAN DEN BERGH, Joroen. (2015), "Participation in protected areas: a social network case study in Catalonia, Spain", in Ecology and Society, 20(4): 45-55

CARLSSON, Lars \& SANDSTRÖM, Annica Charlotte . (2008), "Network governance of 
the commons", in International Journal of the Commons, 2(1): 33-54.

CARLSSON, Lars \& BERKES, Fikret. (2005), "Co-management: concepts and methodological implications", in Journal of Environmental Management, 75(1): 65-76.

CARLSSON, Lars. (2000), "Policy networks as collective action", in Policy Studies Journal, 28(3): 502-20.

COLEMAN, James. (1990), Foundations of social theory. Cambridge, MA, Belknap Press.

COLEMAN, William. D \& PERL, Anthony. (1999), "International policy environments and policy network analysis", in Political Studies, 47(4): 691-709.

COOK, Karen, EMERSON, Richard; GILLMORE, Mary \& YAMAGISHI, Toshio. (1983), "The distribution of power in exchange networks: theory and experimental results", in American Journal of Sociology, 89(2): 275-305.

CREADO, Eliana; MENDES, Ana Beatriz; FERREIRA, Lúcia \& CAMPOS, Simone. (2012), "O Parque Nacional do Jaú e os moradores de sua parte central: agência ou sujeição?”, in Revistas VITAS, (2): $1-35$.

CREADO, Eliana; MENDES, Ana Beatriz; FERREIRA, Lúcia \& CAMPOS, Simone. (2008), "Entre 'tradicionais' e 'moradores': negociaçôes de direitos em duas unidades de conservaçao da Amazônia brasileira", in Ambiente \& Sociedade, 11(2): 255-71.

CRONA, Beatrice \& BODIN, Örjan. (2006), "What you know is who you know? Communication patterns among resource users as a prerequisite for co-management", in Ecology and Society, 11(2): 1-23.

DOUGILL, Andy.; FRASER, E. D. G.; HOLDEN, J.; HUBACEK, K.; PRELL, C.; REED, M. S.; STAGL, S. \& STRINGER; L. C. 2006. "Learning from doing participatory rural research: lessons from the Peak District National Park", in Journal of Agricultural Economics, 57(2): 259-75.

FERREIRA, Lúcia; CAMPOS, Simone; CREADO, Eliana; MENDES, Ana Beatriz \& CAROPRESO, Camilo. (2007), "Encontro das águas: dinâmicas sociais e biodiversidade na Amazônia Brasileira", in Teoria \& Pesquisa 50, 16(1): 15-38.

FREEMAN, Linton. (1979), "Centrality in social networks conceptual clarification", in Social Networks, 1(1978/79): 215-39.

FRIEDKIN, Noah. (1981), "The development of structure in random networks: an analysis of the effects of increasing network density on five measures of structure", in Social Networks 3(1): 41-52.

GIRALDO, Gloria; MORALES, Juan \& VAHOS, James. (2009), "Las políticas públicas territoriales como redes de política pública y gobernanza local: la experiencia de diseño y formulación de las políticas públicas sobre desplazamiento forzado en el Departamento de Antioquia y la ciudad de Medellín”, in Estudios Políticos, (35): 81-105.

GRANOVETTER, Mark. (2007), "Ação econômica e estrutura social: o problema da imersão", in RAE Eletrônica, 6(1): 1-40.

HJERN, Benny. \& PORTER, David. (1997), "Implementation structures: a new unit of administrative analysis", in HILL, Michael (org.). The policy process: a reader. London: Harvester Wheatsheaf, p. 226-240.

IKKINK, Karen; VAN TILBURG, Theo. (1999), "Broken ties: reciprocity and other factors affecting the termination of older adults' relationships", in Social Networks, 21: 131-46.

JACAÚNA, Tiago. (2018), "Difusão horizontal e vertical da política ambiental na Amazônia", in Novos Cadernos NAEA, 21(2): 233-256.

JESSOP, Bob. (1998), "The rise of governance and the risks of failure: the case of economic development", in International Social Science Journal, 50(155): 29-45.

KICKERT, Walter; KLIJN, Erik-Hans; KOPPENJAN, Joop. (1997), "Public management and network management", in W. KICKERT; E-H. KLIJN \& J. KOPPENJAN (orgs.). Managing Complex Networks. London, Sage, p. 35-61.

KNOKE, David \& KUKLINSKI, James. (1982), Network Analysis. Newbury Park, Chisholm, CA, Sage. 
KOOIMAN, Jan. (2003), Governing as Governance. Londres, SAGE.

LIN, Nan. (2001), Social capital: a theory of social structure and action. Cambridge, Cambridge University Press.

LUBELL, Mark. (2004), "Resolving conflict and building cooperation in the National Estuary Program”, in Environmental Management, 33(5): 677-91.

MARQUES, Eduardo. (1999), "Redes sociais e instituiçóes na construção do Estado e da sua permeabilidade", in Revista Brasileira de Ciências Sociais, 14(41): 45-67.

MARQUES, Eduardo. (1998), Redes Sociais e Permeabilidade do Estado: instituiçóes e atores politicos na produção da infra-estrutura urbana no Rio de Janeiro. Tese de doutorado. Universidade Estadual de Campinas, Campinas.

MARSH, David. (2008), "Understanding british government: analyzing competing models", in Journal of Politics and International Relations, 10(1): 251-268.

MARSH, David \& SMITH, Martin. (2000), "Understanding policy networks: towards a dialectical approach”, in Political Studies, 48(1): 4-21.

MARSH, David. (1998), Comparing policy networks. Buckingham/Philadelphia, Open University Press.

MEULEMAN, Louis. (2009), "The cultural dimension of metagovernance: why governance doctrines may fail”, in Public Organization Review, 10(1): 49-70.

NORTH, Douglass. (1990), Institutions, Institutional Change, and Economic Performance. New York, Cambridge University Press.

OSTROM, Elinor. (2005), Understanding institutional diversity. New Jersey, USA, Princeton University Press.

PIERRE, Jon \& Peters, B. Guy. (2000), Governance, politics and the state. London, Macmillan.

PLUMMER, Ryan \& FITZGIBBON, John. (2004), "Some observations on the terminology in cooperative environmental management", in Journal of Environmental Management, 70(1): 63-72.
PRELL, Christina. (2011), Social network analysis: history, theory and methodology. London, Sage.

RAMIA, Gaby, PATULNY, Roger; MARSTON, Greg \& CASSELLS, Kyla. (2017), “The relationship between governance networks and social networks: progress, problems and prospects", in Political Studies Review, 16(4): 331-341.

RATHWELL, Kaitlyn \& PETERSON, Garry. (2012), "Connecting social networks with ecosystem services for watershed governance: a social-ecological network perspective highlights the critical role of bridging organizations", in Ecology and Society, 17(2): 24.

REIS, Bruno. (1995), "Corporativismo, pluralismo e conflito distributivo no Brasil", in Dados, 38(3): 417-457.

Rhodes, R.A.W. (1997), "Foreword”, in W. KICKERT; E-H. KLIJN \& J. KOPPENJAN (orgs.), Managing Complex Networks: Strategies for the Public Sector, pp. xi-xv. London, Sage.

Rhodes, R.A.W. (2007), Understanding governance: ten years on. Leicester, Montfort University, 2007.

SALPETEUR, Matthieu; CALVET-MIR; Laura; DIAZ-REVIRIEGO, Isabel \& REYES-GARCÍA, Victoria. (2017), "Networking the environment: social network analysis in environmental management and local ecological knowledge studies", in Ecology and Society, 22(1): 41.

SANDSTRÖM, Annica \& ROVA, Carl. (2010a), "Adaptive co-management networks: a comparative analysis of two fishery conservation areas in Sweden", in Ecology and Society, 15(3): 14.

SANDSTRÖM, Annica \& ROVA, Carl. (2010b), "The network structure of adaptive governance-a single case study of a fish management area", in International Journal of the Commons, 4(1): 528-551.

SANDSTRÖM, Annica \& CARLSSON, Lars. (2008), "The performance of policy networks: the relation between network structure and network performance", in Policy Studies Journal, 36(4): 497-524.

SCHNEIDER, Mark; SCHOLZ, John; LUBELL, Mark; MINDRUTA, Denisa \& EDWARDSEN, Matthew. (2003), "Building consensual institutions: 
networks and the national estuary program", in American Journal of Political Science, 47(1): 143-58.

SCOTT, John. (2000), Social network analysis. 2. ed. London, Sage.

SINGLETON, Sara. (1998), Constructing Cooperation: the evolution of institutions of co-management. Ann Arbor, University of Michigan Press.

SØRENSEN, Eva \& TORFING, Jacob. (2009), "The European Governance Debate", in 21st
IPSA World Congress of Political Science, 2009, Santiago, Chile.

THATCHER, Mark. (1998), "The development of policy network analysis: from modest origins to overarching framework", in Journal of Theoretical Politics, 10(4): 389-416.

WASSERMAN, Stanley \& FAUST, Katherine. (1994), Social network analysis: methods and applications. Cambridge, Cambridge University Press. 


\section{COMO SE GOVERNA A AMAZÔNIA? REDES SOCIAIS E GOVERNANÇA AMBIENTAL EM UNIDADES DE CONSERVAÇÁO}

Tiago da Silva Jacaúna

Palavras-chave: Redes; Governança Ambiental; Unidades de Conservação.

As políticas de conservação ambiental na Amazônia são caracterizadas pela multiplicidade de atores e interesses locais inseridos em redes. Assume-se que essas redes influenciam e são influenciadas pela (i) dinâmica das relaçóes de poder; (ii) as posiçóes dos atores na rede; (iii) a densidade da rede; (iv) a diversidade, (v) os tipos de interação. Esses componentes ajudam a avaliar os mecanismos de colaboração e/ou conflito no processo de governança. Dessa maneira, para compreender o processo político e a governança ambiental em Unidades de Conservação (UCs), realizou-se pesquisa empírica no Parque Nacional (PARNA) do Jaú, Reserva Extrativista (RESEX) do Rio Unini e Reserva de Desenvolvimento Sustentável (RDS) do Amanã. Os resultados revelam que o Estado, ONGs e moradores estão imersos em uma rede heterogênea, com nível de fechamento de moderado a alto, apresentando ora uma concentração de poder com cooperação hierárquica, ora um poder fragmentado com cooperação horizontal.

\section{HOW IS THE AMAZON GOVERNED? NETWORKS AND ENVIRONMENTAL GOVERNANCE IN PROTECTED AREAS}

Tiago da Silva Jacaúna

Keywords: Networks; Environmental Governance; Protected Areas.

Many actors and local interests embedded in networks characterize environmental conservation policies in the Brazilian Amazon. This paper assumes that these networks both influence, and are influenced by (i) power relation dynamics; (ii) the position of the actors in the network; (iii) density of the network; (iv) diversity; and (v) types of interaction. These components help to assess collaboration and/or conflict resolution mechanisms in the governance process. This study conducted fieldwork in the Jaú National Park, in the Rio Unini Extractive Reserve, and in the Amaná Sustainable Development Reserve in order to understand the policy process and environmental governance in protected areas in the Brazilian Amazon. Results show that the Federal Government, NGOs, and local inhabitants are embedded in a heterogeneous network which is closed up to a moderate level or even up to a high one, revealing either a concentration of power with hierarchical cooperation or fragmented power relations with horizontal cooperation.

\section{COMMENT L'AMAZONIE EST-ELLE GOUVERNÉE ? RÉSEAUX SOCIAUX ET GOUVERNANCE ENVIRONNEMENTALE DANS LES UNITÉS DE CONSERVATION}

Tiago da Silva Jacaúna

Mots-clés: Réseaux; Gouvernance environnementale; Unités de conservation.

Les politiques de conservation de l'environnement en Amazonie se caractérisent par la multiplicité des acteurs et des intérêts locaux immergés dans des réseaux. Ces réseaux influencent et sont influencés par: (i) la dynamique des relations de pouvoir; (ii) la disposition des acteurs dans le réseau; (iii) la densité; (iv) la diversité et (v) le type d'interaction entre les acteurs. Ces éléments conduisent et aident à comprendre les mécanismes de collaboration et/ou de conflit dans le processus de gouvernance. Pour comprendre le processus politique et la gouvernance environnementale dans les zones protégées de l'Amazonie brésilienne, nous avons développé une recherche empirique dans le Parc National (PARNA) du Jaú, de la Réserve d'Exploitation Durable (RESEX) de la Rivière Unini et de la Réserve de Développement Durable (RDS) d'Amanã. Les résultats montrent que l'État, les ONG et les habitants sont immergés dans un réseau hétérogène, avec des niveaux de fermeture qui varient de modérés à élevés, concentrant le pouvoir soit avec une coopération hiérarchique, soit de forme fragmentée avec une coopération horizontale. 